\title{
Management of Spontaneous Spinal Discitis and Spondylodiscitis in Older People
}

\author{
Mohamed Adel Ghoneim*, Waleed Abbass \\ Department of Neurosurgery, Faculty of Medicine, Cairo University, Cairo, Egypt \\ Email: *madel1981@hotmail.com
}

How to cite this paper: Ghoneim, M.A. and Abbass, W. (2020) Management of Spontaneous Spinal Discitis and Spondylodiscitis in Older People. Open Journal of Modern Neurosurgery, 10, 182-191. https://doi.org/10.4236/ojmn.2020.101019

Received: December 21, 2019

Accepted: January 18, 2020

Published: January 21, 2020

Copyright $\odot 2020$ by author(s) and Scientific Research Publishing Inc. This work is licensed under the Creative Commons Attribution International License (CC BY 4.0).

http://creativecommons.org/licenses/by/4.0/

(c) (i) Open Access

\begin{abstract}
Introduction: Spontaneous spinal infection is an uncommon disease, although the incidence is increasing in the last years. Absence of specific symptoms, and delayed diagnosis result in high morbidity, and mortality. Aim of the Study: To assess the clinical status of the patients, laboratory markers of inflammation, radiological findings, causative organisms, methods of management and their outcome. Patients and Method: Prospective study of 14 patients having spontaneous spinal infection from April 2017 to June 2019. Results and outcome: The study included eight males and six females with mean age of 43.1 years. On Denis pain score, six patients were P5 and eight patients were P4. Fever was found in nine patients. As regards ASIA score, seven patients were ASIA score E (normal motor, and sensory function), six patients were ASIA score D and one patient ASIA score C. Nine patients were found to be diabetic. Laboratory markers of inflammation were elevated in all patients. Two patients were managed conservatively (14.3\%) (two cases were TB infection). Twelve patients were managed surgically (85.7\%), six of them were TB infection (50\%), three were nonspecific infection (25\%), one patient was Staph aureus, one streptococci, and one brucella contributing to (8.3\%) for each. There was improvement of neurological condition as eleven patients became ASIA score E, and three $\mathrm{D}$ and pain had also improved in all patients, ten patients became Denis P1, and four P2. Conclusions: Early diagnosis of spontaneous spinal infection depends on clinical sense to detect patients with back or cervical pain associated with fever and elevated laboratory markers of inflammation. A diagnosis was proved by MRI. Not all cases of Spinal infection need surgery. The indication of surgery is the presence of neurological deficit, spinal instability and failure of medical treatment in case of severe pain. Tuberculosis was the commonest organism as it is endemic in Egypt.
\end{abstract}

\section{Keywords}

Spondylodiscitis, Diabetes Mellitus, Tuberculosis 


\section{Introduction}

Spontaneous spinal infection, is an uncommon infectious condition, the symptoms may be unspecified, as fever, localized tenderness, and neurological manifestations due to the deformity of the structures affected [1] [2]. The incidence is increasing in the last years [3]. The course is either acute or chronic, due to absence of specific symptoms and the diagnosis is usually delayed resulting in high morbidity and mortality [4]. There are risk factors in majority of the patients like diabetes mellitus, alcoholism, HIV infection, or a possible local or systemic infection [5]. The condition is classified according to the affected anatomical structure to vertebral osteomyelitis, discitis, spondylodiscitis, spinal canal infections, and nearby soft tissue infections. In adult, the individual discitis is rare and the expression of osteomyelitis and spondylodiscitis are more relevant [6], but sometimes present in pediatric patients [7]. The way of spread of pathogens to spine is either haematogenous spread mainly arterial, direct external inoculation, or spread from neighboring tissue [8]. The improvement in diagnostic radiological methods like CT guided biopsy and the MRI definitely helps in accurate diagnosis and improves the outcome after management. MRI is the investigation of choice in diagnosis of spondylodiscitis and is highly sensitive and specific in diagnosis of the infection of neural structure [9]. The aim of treatment is to eliminate infection, maintain structure and function of the spine, and relieve pain [6]. There was an improvement in management of spondylodiscitis in the last years as a result of improvement of antibiotics and surgical treatment which led to improvement of outcomes [10]. In Potts disease, antituberculous drugs are given for nine to twelve months whether the patients will be treated medically or surgically [10]. In pyogenic cases, antibiotic is given intravenously for about three to eight weeks followed by orally antibiotic for about $6-12$ weeks [11].

Aim of the study: To assess the demographics, clinical features, past medical history, laboratory tests of inflammation, level of the infection, causative organism, management, and outcome.

\section{Patients and Methods}

Prospective study of 14 patients having spontaneous spinal infections was managed in Cairo University Hospitals from April 2017 to June 2019. We included Patients more than 18 years, both sex, and had spontaneous spinal infection in the form of spondylodiscitis, and spinal epidural abscess managed either medically or surgically. We excluded iatrogenic cases. History, Examination, and investigations were used to assess the demographics, clinical features, past medical history, laboratory tests of inflammation, level of the infection, causative organism, management, and outcome. History included age, sex, and patient's symptoms focusing on neurological symptoms, motor affection, sensory affection or sphincteric disturbance. Past history of associated medical disorders such as diabetes. Denis functional pain scale (Table 1) [12] was used to assess the pain. Neurological examination was done including sensory and motor examination 
and reflexes examination. ASIA score (Table 2) [13] was used to assess neurological deficits of limbs. Investigations were done including laboratory markers of inflammation [white blood cell count (WBC), erythrocyte sedimentation rate (ESR), and C-reactive protein (CRP)], organism identification by culture done after surgery, or CT guided biopsy for medically treated cases. MRI with contrast (Figures 1-3) in all cases was used to assess spinal level, extension of infection.

Table 1. Denis' functional pain scale [12].

\begin{tabular}{cc}
\hline Pain scale criteria & Score \\
No pain & 1 \\
Minimum pain, without use of medication & 2 \\
Moderate pain, with occasional use of medication & 3 \\
Moderate to severe pain, with constant use of medication & 4 \\
Severe pain, with chronic use of medication & 5 \\
\hline
\end{tabular}

Table 2. ASIA SCORE [13].

DESCRIPTION

GRADE

Complete: No motor or sensory function is preserved in the sacral segments S4-5.

Incomplete: Sensory but not motor function is preserved below the neurological level and includes the sacral segments S4-5.

B

Incomplete Motor function is preserved below the neurological level and the majority of key muscles below the neurological level have a muscle grad less than 3 .

Incomplete Motor function is preserved below the neurological level and the majority of key muscles below the neurological level have a muscle grade greater than 3 .

Normal: Motor and sensory function are normal.

(1)

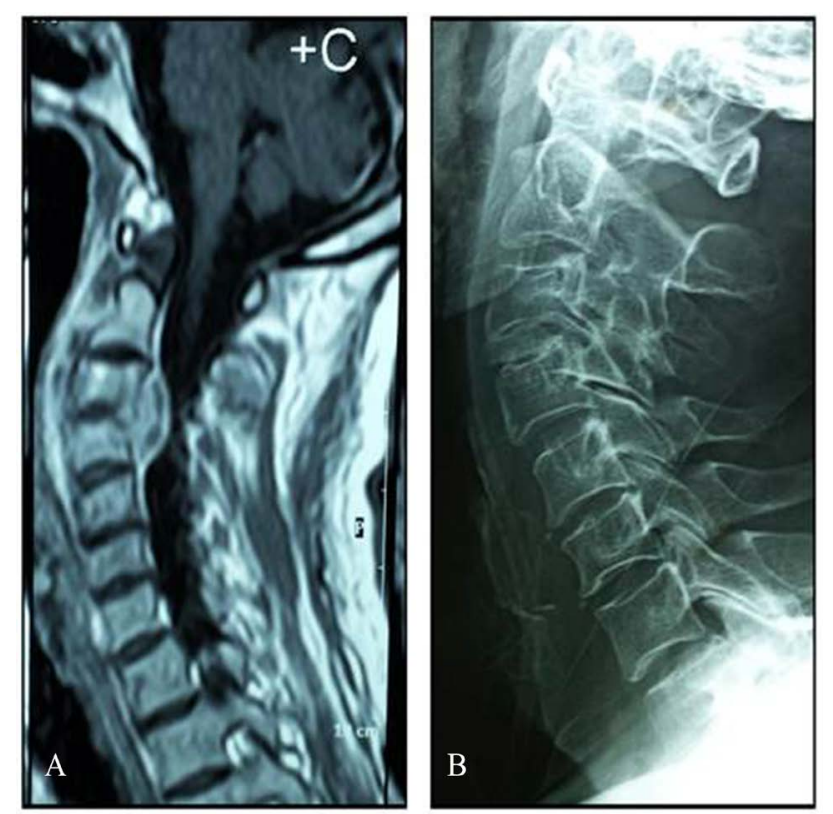

Figure 1. MRI cervical (A) show C3-4 spondylodiscitis and epidural abscess operated upon by anterior approach and bone graft in C3-4 Disc space (B). 

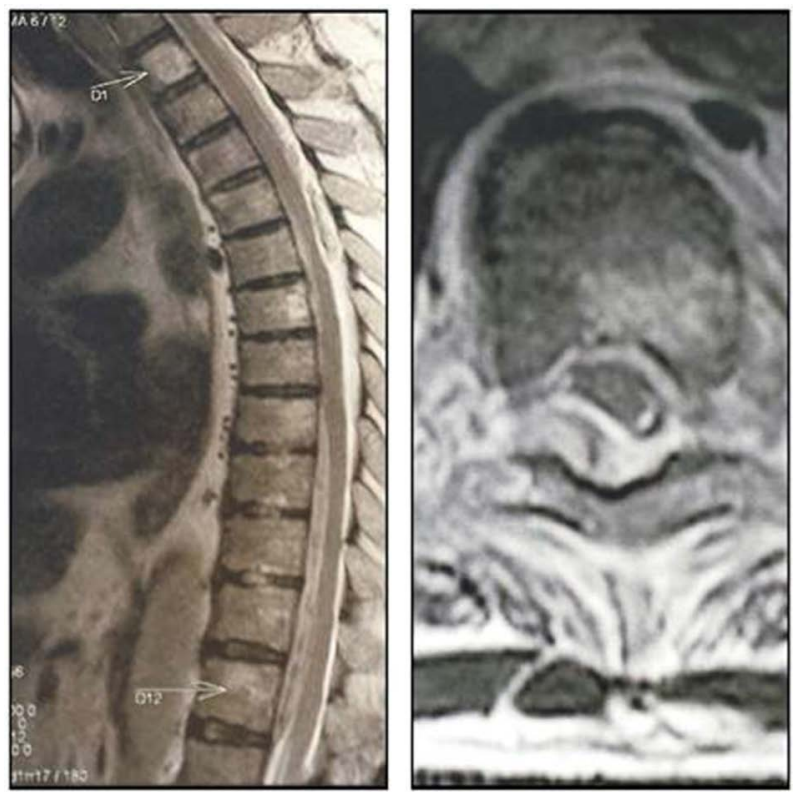

Figure 2. Epidural collection indenting the cord of dorsal Spine operated upon by laminectomy without fixation.
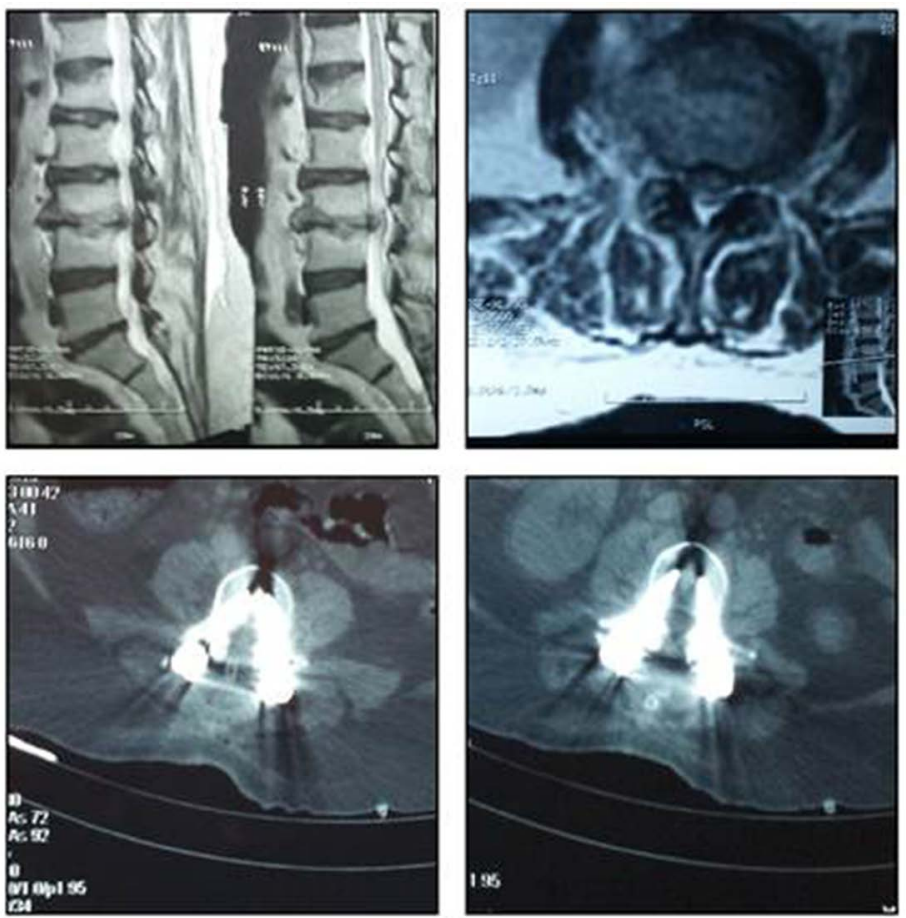

Figure 3. (Up) MRI LSS show L3-4 Spondylodiscitis operated by Posterior laminectomy and Fixation (Down).

radiological features which suggest spondylodiscitis include increasing signal of the intervertebral disc on T2 image, edema in vertebral body marrow, enhancement of vertebral body and disc, inflammation of epidural or paraspinal extension. Management of the patients twelve patients had been treated surgically (85.7\%), six of them were operated upon by posterior approach decompressive 
laminectomy with fixation (50\%), three of them were lumbar posterior fixation and three were dorsal posterior fixation. Three patients were operated upon by anterior surgical approach (25\%) all of them were cervical, to drain the pus and bone graft Insertion in disc space, and three patients were operated upon by posterior decompressive laminectomy alone (25\%) one was dorsal and the other two were lumbar. Two cases were conservatively managed (14.3\%) and received antimicrobial treatment (two cases were tuberculosis) and CT guided biopsy was done in medically treated patients to know the pathogen.

All patients were followed up at intervals of 1 week, 3 months, 6 months Follow up of patients include clinical evaluation and laboratory investigation.

\section{Results}

The epidemiological and clinical data of the patients are shown in (Table 3). The study included 14 patients 8 were males $(57.1 \%)$ and 6 were females $(42.9 \%)$ their age ranging from 23 to 65 years with the mean age of 43.1 years. Pain was assessed by (Denis score); in the pre management six patients were P5 (42.9\%). Four patients of them were tuberculosis, one patient was nonspecific infection (no organism detected), and one patient was Staph aureus. Eight patients were P4 (57.1\%) distributed as four patients were tuberculosis, two patients were nonspecific infection and one patient was brucella infection, and one patient was Strep Viridans. The result of neurological assessment by ASIA score; seven patients were normal with ASIA score E (50\%), five of them were managed surgically and two were managed medically, six patients were ASIA score D (42.9\%) all of them were managed surgically. one patient was ASIA score C (7.1\%) and was managed surgically. The laboratory markers of inflammation were raised in all patients. Diabetes mellitus was present in 11 patients and all uncontrolled with

Table 3. Epidemiological and clinical data of patients at presentation.

\begin{tabular}{cc}
\hline 14 & NO of the patients \\
\hline 43.1 years & Mean age \\
$8(57.1 \%)$ & Male \\
$6(42.9 \%)$ & Female \\
$3(21.4 \%)$ & Cervical \\
$5(35.7 \%)$ & Dorsal \\
$6(42.9 \%)$ & Lumbosacral \\
$11(78.6 \%)$ & DM \\
Elevated in all patients $(100 \%)$ & Laboratory markers of inflammation \\
P5 $\{6$ patients $(42.9 \%)\}$ & Denis score \\
P4 $\{8$ patients $(57.1 \%)\}$ & \\
$\mathrm{E}\{7$ patients $(50 \%)\}$ & ASIA score \\
D $\{6$ patients $(42.9 \%)\}$ & \\
C $\{1$ patient $(7.1 \%)\}$ &
\end{tabular}


elevated concentrations of glycosylated hemoglobin A1. The site of pathology six patients (42.9\%) were in lumbar spine, five patients (35.7\%) were in dorsal spine, and there were three patients (21.4\%) in cervical spine. The levels of infection of all patients were diagnosed by MRI studies (Figures 1-3, Table 4). Seven Patients had both epidural and paraspinal infections. The causative organism; in eight patients (57.1\%) Mycobacterium tuberculosis (pott's disease) were identified four cases in lumbar spine (50\%) and four cases in dorsal spine (50\%), while three patients (21.4\%) were due to Non specific infection (no organism detected) two cases were cervical and one case was lumbar spine, one (7.1\%) patient was due to Brucella infection in lumbar spine. One patient (7.1\%) patient was due to streptococci infection in dorsal spine, and finally one patient (7.1\%) was due to Staph aureus infection in cervical spine (Table 4).

Twelve patients had been treated surgically (85.7\%), six of them were TB infection (50\%), three were nonspecific infection (25\%) while one was Staph aureus (8.3\%), one was streptococci (8.3\%) and one brucella (8.3\%) (Table 5).

Outcome: There was improvement of neurological and pain outcomes in the follow up of the patients. There was improvement of neurological condition by ASIA score after management the seven patients with ASIA score E before management became eleven patients (78.6\%) after management four of them were ASIA score D and turned after surgical management to ASIA E. Three patients (21.4\%) were ASIA score D after management, one of them was ASIA score $\mathrm{C}$ and turned after surgery to $\mathrm{D}$ and two were $\mathrm{D}$ and remained $\mathrm{D}$ even

Table 4. Causative agents and site of lesion of the patients with spondylodiscitis.

8 patients (57.1\%) Mycobacterium tuberculosis (pott's disease) $\{4$ Lumbar, 4 Dorsal $\}$

3 patients $(21.4 \%)$ were due to Non specific infection. $\{2$ Cervical, 1 Lumbar $\}$ 1 patient $(7.1 \%)$ was due to Brucella infection. $\{$ Lumbar $\}$

Causative organism 1 patient $(7.1 \%)$ was due to streptococci infection. \{Dorsal\} 1 patient $(7.1 \%)$ was due to Staph aureus infection. $\{$ cervical $\}$

Site of Lesion

Cervical

3 Patients $(21.4 \%)$

Dorsal

6 Patients $(42.9 \%)$

Lumbosacral

Table 5. Management and follow-up of the patients.

\begin{tabular}{cc}
\hline & Management \\
\hline 3 were managed by anterior surgical approach & Cervical \\
4 of them were managed surgically and 1 conservative & Dorsal \\
5 of them were managed surgically and 1 conservative & Lumbosacral \\
P1 $\{10$ patients $(71.4 \%)\}$ managed surgically 1 medically & Denis score post management \\
P2 $\{4$ patients $(28.6 \%)\} 3$ managed surgically 1 medically & \\
E $\{11$ patients $(78.6 \%)\}$ & ASIA score post management \\
\hline
\end{tabular}


after surgery, and pain also improved in all patients; in ten patients $(71.4 \%)$ became $\mathrm{P} 1$ nine of them were managed surgically and one managed by medical treatment. Four patients (28.6\%) were P2 (three of them were managed surgically and one was managed medically) (Table 5).

\section{Discussion}

Spontaneous spinal infections management is a debatable condition in neurosurgery due to the multiplicity of causative organisms and the various methods accessible for management. In majority of cases, there is a risk factor like diabetes mellitus, HIV infection, or local or systemic source of infection [5]. In our study uncontrolled DM was found in eleven Cases (78.6\%). Spondylodiscitis was more common in patients more than 40 years [14] in our study the mean age was 43.1 years.

Diagnosis is depending on clinical manifestations, presence of back or cervical pain associated with fever [15]. In our study all patients had back or cervical pain, elevated laboratory marker of inflammation, fever was found in nine patients (64.3\%) In our study all patients had elevated laboratory markers of inflammation and radiological imaging. MRI is imaging of choice in diagnosis [16]. All cases were diagnosed by MRI in our study. However, the diagnosis may be difficult and delayed as the condition is not common and should be suspected in case of localized back pain associated with unexplained neurological manifestations which occurred only in case of spinal cord or roots affection [17].

Treatment options were medical or surgical, conservative management after CT Guided needle biopsy for organism detection and includes antimicrobial treatment and immobilization [18]. Surgical intervention was indicated in case of neural compression, the aim is decompression of neural tissue, maintenance of structure and restoration of neurological function or spinal instability due to bone destruction. The surgical intervention was indicated also in case of failure of medical treatment in preventing the pain [9]. In our study, males represent (57.1\%) of patients and females (42.9\%), with mean age 43.1 years the percentage of males and females close to the result of Bart et al. [19] in which male $68.8 \%$ and females $31.2 \%$ but mean age older 64.3 years.

In our study, lumbar spine infection was found in (42.9\%), dorsal spine infection in (35.7\%), and cervical spinal infection in (21.4\%). Close to Bart et al. [19] with differences of multiple sites as Cervicothoracic and, Thoracolumbar which were not presented in our study possibly due to small number of cases.

In our study, the causative organism was Mycobacterium tuberculosis (pott's disease) in $(57.1 \%)$ of patients, $(21.4 \%)$ were due to Non specific infection (no organism detected), (7.1\%) was due to Brucella, (7.1\%) was due to streptococci infection, and (7.1\%) was due to Staph aureus infection. these results were different from Bart et al. [19] in which staphylococcus aureus was the causative organism in $40.5 \%$, streptococci in $26.4 \%$, gram negative bacteria in $14.9 \%$, non specific in $8.3 \%$, and anerobic bacteria was $2.5 \%$. In our results the tuberculosis 
(potts disease) was the most common infection because tuberculosis is endemic in Egypt unlike Bart et al. [19] in France where staphylococcus aureus was the most common organism.

In our study surgical intervention was in (85.7\%) of cases, the approaches used were posterior approach (decompressive laminectomy with fixation) in $50 \%$, posterior decompressive laminectomy in (25\%), and anterior surgical approach in 25\%. Similar to Martín Alonso et al. [20] who did posterior fusion in (42.2\%), Laminectomy \& biopsy (21.7\%), and anterior fusion in (33.7\%). In our study there is improvement in outcome as a regards neurological condition by ASIA score which was ASIA in eleven patients, ASIA D in three patients, and no patients were ASIA C, also the pain improved in all cases after management by Denis score.

Study Limitation: Small number of cases, in future we need cooperation with another centers dealing with same pathology.

\section{Conclusion}

Early diagnosis of spontaneous spinal infection depends on clinical sense to detect patients with back or cervical pain associated with fever and elevated laboratory markers of inflammation. A diagnosis was proved by MRI. Not all cases of spinal infection need surgery. The indication of surgery is the presence of neurological deficit, spinal instability and failure of medical treatment in case of severe pain. Tuberculosis was the commonest organism as it is endemic in Egypt.

\section{Conflicts of Interest}

The authors declare no conflicts of interest regarding the publication of this paper.

\section{References}

[1] Lehovsky, J. (1999) Pyogenic Vertebral Osteomyelitis/Disc Infection. Bailliere's Best Practice \& Research. Clinical Rheumatology, 13, 59-75. https://doi.org/10.1053/berh.1999.0006

[2] Khan, I.A., Vaccaro, A.R. and Zlotolow, D.A. (1999) Management of Vertebral Diskitis and Osteomyelitis. Orthopedics, 22, 758-765.

[3] Ledermann, H.P., Schweitzer, M.E., Morrison, W.B. and Carrino, J.A. (2003) MR Imaging Findings in Spinal Infections: Rules or Myths? Radiology, 228, 506-514. https://doi.org/10.1148/radiol.2282020752

[4] Hopkinson, N., Stevenson, J. and Benjamin, S. (2001) A Case Ascertainment Study of Septic Discitis: Clinical, Microbiological and Radiological Features. QJM, 94, 465-470. https://doi.org/10.1093/qjmed/94.9.465

[5] Forestier, E., Sordet, C., Cohen-Solal, J., Remy, V., Javier, R.M., Kuntz, J.L. and Sibilia, J. (2006) Bone and Joint Infection Due to Streptococcus pneumoniae in Two Immunocompetent Adults. Joint Bone Spine, 73, 325-328. https://doi.org/10.1016/j.jbspin.2005.07.004

[6] Torrie, P.A., Leonidou, A., Harding, I.J., Wynne Jones, G., Hutchinson, M.J. and 
Nelson, I.W. (2013) Admission Inflammatory Markers and Isolation of a Causative Organism in Patients with Spontaneous Spinal Infection. Annals of the Royal College of Surgeons of England, 95, 604-608.

https://doi.org/10.1308/rcsann.2013.95.8.604

[7] Nussbaum, E.S., Rigamonti, D., Standiford, H., Numaguchi, Y., Wolf, A.L. and Robinson, W.L. (1992) Spinal Epidural Abscess: A Report of 40 Cases and Review. Surgical Neurology, 38, 225-231. https://doi.org/10.1016/0090-3019(92)90173-K

[8] Duarte, R.M. and Vaccaro, A.R. (2013) Spinal Infection: State of the Art and Management Algorithm. European Spine Journal, 22, 2787-2799. https://doi.org/10.1007/s00586-013-2850-1

[9] Leone, A., Dell'Atti, C., Magarelli, N., Colelli, P., Balanika, A., Casale, R. and Bonomo, L. (2012) Imaging of Spondylodiscitis. European Review for Medical and Pharmacological Sciences, 16, 819.

[10] Perronne, C., Saba, J., Behloul, Z., Salmon-Céron, D., Leport, C., Vildé, J.L. and Khan, M.F. (1994) Pyogenic and Tuberculous Spondylodiskitis (Vertebral Osteomyelitis) in 80 Adult Patients. Clinical Infectious Diseases, 19, 746-750.

https://doi.org/10.1093/clinids/19.4.746

[11] Livorsi, D.J., Daver, N.G., Atmar, R.L., Shelburne, S.A., White, A.C. and Musher, D.M. (2008) Outcomes of Treatment for Hematogenous Staphylococcus aureus Vertebral Osteomyelitis in the MRSA ERA. Journal of Infection, 57, 128-131. https://doi.org/10.1016/j.jinf.2008.04.012

[12] Denis, F. (1983) The Three Column Spine and Its Significance in the Classification of Acute Thoracolumbar Spinal Injuries. Spine (Phila Pa 1976), 8, 817-831. https://doi.org/10.1097/00007632-198311000-00003

[13] Roberts, T.T., Leonard, G.R. and Cepela, D.J. (2017) Classifications in Brief: American Spinal Injury Association (ASIA) Impairment Scale. Clinical Orthopaedics and Related Research, 475, 1499-1504. https://doi.org/10.1007/s11999-016-5133-4

[14] Belzunegui, J., Intxausti, J.J., De Dios, J.R., Del val, N., Rodriguez, V., Gonzalez, C., Queiro, R. and Figueroa, M. (2000) Haematogenous Vertebral Osteomyelitis in the Elderly. Clinical Rheumatology, 19, 344-347. https://doi.org/10.1007/PL00011175

[15] Fica, A., Bozan, F., Aristegui, M., et al. (2003) Spondylodiscitis. Analysis of 25 Cases. Revista Medica de Chile, 131, 473-482. https://doi.org/10.4067/S0034-98872003000500001

[16] Phadke, D.M., Lucas, D.R. and Madan, S. (2001) Fine Needle Aspiration Biopsy of Vertebral and Intervertebral Disc Lesions: Specimen Adequacy Diagnostic Utility, and Pitfalls. Archives of Pathology \& Laboratory Medicine, 125, 1463-1468.

[17] Mylona, E., Samarkos, M., Kakalou, E., Fanourgiakis, P. and Skoutelis, A. (2009) Pyogenic Vertebral Osteomyelitis: A Systematic Review of Clinical Characteristics. Seminars in Arthritis and Rheumatism, 39, 107. https://doi.org/10.1016/j.semarthrit.2008.03.002

[18] Rao, G.P. (2000) Spinal Intramedullary Tuberculous Lesion: Medical Management. Report of Four Cases. Journal of Neurosurgery Spine, 93, 137-141. https://doi.org/10.3171/spi.2000.93.1.0137

[19] Bart, G., Redon, H., Boutoille, D., Hamel, O., Planche, L., Maugars, Y. and Le Goff, B. (2016) Is There an Association between Magnetic Resonance Imaging and Neurological Signs in Patients with Vertebral Osteomyelitis? A Retrospective Observational Study on 121 Patients. Medicine (Baltimore), 95, e2373. https://doi.org/10.1097/MD.0000000000002373 
[20] Martín-Alonso, J., Delgado-López, P.D., Castilla-Díez, J.M., Martín-Velasco, V., Galacho-Harriero, A.M., Ortega-Cubero, S., Araus-Galdos, E. and Rodriguez-Salazer, A. (2018) Role of Surgery in Spontaneous Spondylodiscitis: Experience in 83 Consecutive Patients. Neurocirugía (English Edition), 29, 64-78.

https://doi.org/10.1016/j.neucie.2017.12.005 